\title{
Experimental and Numerical Investigation of the Deformation and Fracture Mode of Microcantilever Beams Made of $\mathrm{Cr}(\mathrm{Re}) / \mathrm{Al}_{2} \mathrm{O}_{3}$ Metal-Matrix Composite
}

\author{
WITOLD WEGLEWSKI, PANDI PITCHAI, KAMIL BOCHENEK, \\ GABRIELLA BOLZON, RUTH KONETSCHNIK, BERNHARD SARTORY, \\ REINHOLD EBNER, DANIEL KIENER, and MICHAŁ BASISTA
}

\begin{abstract}
This work presents a combined experimental and computational study of the deformation and fracture of microcantilever specimens made of chromium(rhenium)-alumina metal-matrix composite (MMC), with a particular focus on the failure properties of the metal-ceramic interfaces. The obtained experimental results show that the bending strength of microcantilevers containing alumina particles in critical cross-sections near specimen's fixed end is considerably higher than that of unreinforced chromium(rhenium) samples. Brittle cracking along chromium-alumina interfaces is the dominant fracture mode of the composite microcantilevers. The interface characteristics are determined in an indirect way by numerical simulations of the experiment with account of the actual specimen microstructure from the scanning electron microscope (SEM) images. A parametric study demonstrates that the overall material response may be reproduced by different sets of model parameters, whereas the actual failure mode permits to discriminate among the possible alternatives. Using this approach, the in situ values of the chromium-alumina interface cohesive strength and the fracture energy are estimated.
\end{abstract}

https://doi.org/10.1007/s11661-020-05687-3

(C) The Author(s) 2020

\section{INTRODUCTION}

MiCROSCOPIC deformation mechanisms are often responsible for the macroscopic (observable) material behavior. A logical consequence of this relationship is the steadily growing interest in investigating events on the micron scale by means of micromechanical experiments. For the past decade, we have been witnessing an intensive activity in micromechanical material testing such as compression of micropillars ${ }^{[1,2]}$ or bending of microcantilevers. ${ }^{[3,4]}$ Micromechanical testing can be a challenging task due to several reasons including machining of miniaturized specimens, various size

WITOLD WEGLEWSKI, KAMIL BOCHENEK, and MICHAŁ BASISTA are with the Institute of Fundamental Technological Research, Polish Academy of Sciences, Pawińskiego 5B, 02-106 Warsaw, Poland. Contact e-mail: mbasista@ippt.pan.pl PANDI PITCHAI and GABRIELLA BOLZON are with the Department of Civil and Environmental Engineering, Politecnico di Milano, 20133 Milan, Italy. RUTH KONETSCHNIK and DANIEL KIENER are with the Department of Material Science, Chair of Materials Physics, Montanuniversität Leoben, 8700 Leoben, Austria. BERNHARD SARTORY and REINHOLD EBNER are with the Materials Center Leoben Forschung GmbH, 8700 Leoben, Austria.

Manuscript submitted September 24, 2019.

Article published online February 28, 2020 effects, or precise and repeatable load application. The effect of specimen size on the mechanical strength for specimen sizes ranging from micrometers to millimeters or even centimeters was studied in References 5 and 6.

The results indicate that the measured strength increases with decreasing effectively loaded volume, which is mainly related to the probability of finding defects in the loaded volume of the low-ductility hard metals. ${ }^{[6]}$ Accordingly, sample size-related influences can potentially affect the observed fracture properties, too. ${ }^{[7]}$

Micromechanical bending experiments on microcantilevers manufactured by Focused Ion Beam (FIB) milling were used in the past to measure the elastic constants, ${ }^{[8,9]}$ the fracture toughness ${ }^{[10-12]}$ and the flow stress $^{[13]}$ of single crystals. More recently, they were used for determining the flexural strength of individual ceramic particles extracted from a metal matrix ${ }^{[14]}$ or partially embedded in a metal matrix. ${ }^{[15]}$ These tests proved effective in providing microscale values of the mechanical properties that are particularly needed in numerical simulations of the material behavior.

Metal-matrix composites (MMCs) with ceramic reinforcements are advanced structural materials used in many sectors including aerospace, automotive, railway, electronics and power industries because of their superior performance in demanding in-service conditions 
such as high temperature, high pressure, chemically aggressive environment, complex mechanical loading and combinations thereof. MMCs manifest high stiffness and high-specific strength, enhanced wear resistance and superior thermal properties. ${ }^{[16]}$ The properties of MMCs can be designed for specific applications via a number of factors including the volume fractions, type, shape, size and distribution of the reinforcing phase. ${ }^{[17]}$ The ceramic reinforcement can be in the form of particles, continuous or short fibers, whiskers and other discrete objects. Aluminum alloys and titanium alloys are mostly used by the industry as matrices for MMCs. ${ }^{[18]}$ For specific applications, other metals such as magnesium, iron, chromium, copper or intermetallic compounds (e.g. TiAl, NiAl) are employed. Besides classical MMCs composed of continuous ductile matrices and discrete ceramic reinforcements, there is a newer group of MMCs in which both constituent phases are continuous: the so-called interpenetrating phase composites (IPC) usually produced by pressure-assisted infiltration of a molten metal into a porous ceramic preform. ${ }^{[19]}$

To obtain an MMC with desired properties, the choice of materials for the matrix and the reinforcement must be made together with the selection of a proper processing method. Among methods used to fabricate MMC liquid state processes (e.g. conventional casting, squeeze casting, spray deposition) and solid state processes (e.g. powder metallurgy, extrusion, forging) should be mentioned. ${ }^{[16,20]}$ Powder metallurgy offers a number of advantages over other fabrication routes of particle-reinforced bulk MMCs, namely good wettability between metal matrix and ceramic reinforcement, homogeneous microstructure of the final composite, and no undesirable phases formed during processing. On the other hand, the liquid state processing techniques often suffer from difficulties in mixing of the constituent phases leading to the agglomeration of ceramic reinforcement, poor wettability between phases, and detrimental reactions occurring at high temperatures. ${ }^{[21]}$

In two-phase ductile-brittle materials, such as metal matrix composites reinforced with ceramic particles, the interface between the matrix and the reinforcement plays a dominant role in the overall material response to mechanical loading. Therefore, the interfacial strength and fracture toughness are among the factors of primary importance in producing stronger and tougher MMCs. Despite the considerable progress in micromechanical testing techniques, the determination of both the interfacial strength and fracture toughness is still difficult to achieve. A remedy has been sought in combining micromechanical tests with simultaneous SEM observations. However, a research gap still exists since the in situ measurements of the failure properties of the interfaces between the metal matrix and ceramic particles of the micrometer size are a prohibitive task. This work is an attempt to fill up this gap by proposing an inverse numerical analysis of the results from micromechanical tests to infer the missing properties on the microscale. In other words, the obtained experimental results (e.g. micro force-displacement curves and deformation patterns) will be used as input data in the finite element model predicting the micro specimen behavior with a sufficient accuracy. One output of this model will be a credible estimation of the cohesive strength and fracture energy of the interface.

This study concerns the microscopic deformation and fracture mechanisms of a sintered chromium(rhenium)-alumina composite subjected to micromechanical bending. This metal-ceramic composite is investigated in view of its potential application in valve seats of internal combustion engines using alternative fuels such as compressed natural gas (CNG), hydrogen, or liquefied petroleum gas (LPG). This innovative material solution for the valve seats was tested in a car engine in laboratory conditions and is now being prepared at the Institute of Fundamental Technological Research of Polish Academy of Sciences in Warsaw for testing in real traffic conditions. While the wear resistance and heat dissipation capability are the most critical properties for the valve seat materials, even the mechanical response to loading of these potentially brittle material systems needs to be reliably predicted and verified.

In general terms, this work is aiming for a better understanding of the local deformation and fracture behavior of $\mathrm{Cr}(\mathrm{Re}) / \mathrm{Al}_{2} \mathrm{O}_{3} \quad \mathrm{MMC}$ manufactured by powder metallurgy. The specific objectives encompass: (i) in situ experimental identification of the deformation and failure modes of the FIB-milled microcantilevers loaded by a nanoindenter, and (ii) numerical simulation of the bending experiments to predict the cohesive strength and fracture energy of the interface between $\mathrm{Al}_{2} \mathrm{O}_{3}$ particles and $\mathrm{Cr}(\mathrm{Re})$ matrix on the microscale. The latter objective is of particular interest since the microscale values of the interface properties needed in MMCs modeling are often lacking.

\section{MATERIALS AND METHODS}

\section{A. Material}

The material used in micromechanical tests was a chromium(rhenium)-alumina composite obtained by powder metallurgy. Rhenium powder (5 vol pct) was added to the $95 \mathrm{vol}$ pet of the mixture of $75 \mathrm{vol}$ pct $\mathrm{Cr}+25$ vol pet $\mathrm{Al}_{2} \mathrm{O}_{3}$ to improve macroscopic mechanical, thermal and wear properties of the composite with respect to its intended application in valve seats. The effect of rhenium addition on the properties of $\mathrm{Cr}(\mathrm{Re}) / \mathrm{Al}_{2} \mathrm{O}_{3} \mathrm{MMC}$ was already investigated and summarized in References 22 through 24 and will not be addressed here.

The samples for micromechanical testing were produced at the Institute of Fundamental Technological Research of Polish Academy of Sciences in Warsaw by the powder metallurgy method using commercial powders of chromium (producer F.W. Winter, purity 99.5 pct), rhenium (KGHM Ecoren S.A., purity min. 99.9 pct) and $\alpha$-alumina (New Met Koch, purity 99.99 pet). The average grain size of the starting powders was 2 to $5 \mu \mathrm{m}$ for $\mathrm{Cr}, 5 \mu \mathrm{m}$ for $\alpha-\mathrm{Al}_{2} \mathrm{O}_{3}$ and $4 \mu \mathrm{m}$ for rhenium. The powders were ground for 4 hours with a 15 minute break every 15 minutes at a speed of $200 \mathrm{rpm}$ in a 
planetary ball mill (Fritsch Pulverisette 5). A $250 \mathrm{ml}$ tungsten carbide grinding bowl was used with tungsten carbide balls of $10 \mathrm{~mm}$ diameter (ball to powder weight ratio BPR 5:1).

The milling process was optimized by carrying out a particle size analysis in Malvern Mastersizer 3000 apparatus at different stages of the process. This device uses the laser diffraction technique to measure the sizes of particles. A powder sample dispersed in water passed through the measurement area of the optical bench, where the laser beam illuminated the particles. The light intensity was measured by detectors and then recalculated into particle size distribution pattern. After 4 hours of milling the particles of $\mathrm{Cr}$ and $\mathrm{Al}_{2} \mathrm{O}_{3}$ in the $\mathrm{Cr} / \mathrm{Re} /$ $\mathrm{Al}_{2} \mathrm{O}_{3}$ mixture exhibited no significant reduction in size. On the other hand, the Re particles, which are relatively ductile, decreased in size and decorated harder $\mathrm{Cr}$ and $\mathrm{Al}_{2} \mathrm{O}_{3}$ particles (Figure 1(a)). The size distribution obtained with the Malvern Mastersizer 3000 analyzer was as follows: $D_{\mathrm{v} 10}=0.326 \mu \mathrm{m}, D_{\mathrm{v} 50}=2.48 \mu \mathrm{m}$ and $D_{\mathrm{v} 90}=5.42 \mu \mathrm{m}$ (Figure 1(b)).

After milling of the starting materials, the powder mixture was sintered in a hot press (HP-20-4650, Thermal Technology LLC) at $1400^{\circ} \mathrm{C}$ under $30 \mathrm{MPa}$ pressure. The heating rate was $10^{\circ} \mathrm{C} / \mathrm{min}$ and the samples were held for 30 minutes at the maximum temperature. The cooling process was carried out without sample removal from the press and consisted of two steps: (i) from $1400{ }^{\circ} \mathrm{C}$ to $500{ }^{\circ} \mathrm{C}$ it was pre-set via the HP control panel with a cooling rate of $10{ }^{\circ} \mathrm{C} /$ min and a constant pressure of $30 \mathrm{MPa}$, (ii) from $500{ }^{\circ} \mathrm{C}$ to room temperature it was a free cooling under load-free conditions.

The microstructure of sintered $\mathrm{Cr}(\mathrm{Re}) / \mathrm{Al}_{2} \mathrm{O}_{3}$ bulk composite is shown in Figure 2. Rhenium dissolves in the chromium matrix although its concentration may vary, which was proven by EDX analysis in Reference 22 In the present study, the color gradients in some of the bright phases in the SEM image in Figure 2 indicate that the dissolution of rhenium in the chromium matrix is not completed.

\section{B. Specimen Preparation and Testing Procedure}

The FIB technique combined with Scanning Electron Microscopy (SEM) was employed to fabricate microcantilevers for the bending tests with dimensions of $5 \times 5 \times 21 \mu \mathrm{m}^{3}$. The $\mathrm{Cr}(\mathrm{Re}) / \mathrm{Al}_{2} \mathrm{O}_{3}$ sample was placed in a Cobra-Orsay-Physics setup from which a number of microspecimens were shaped by $\mathrm{Ga}^{+}$FIB milling using

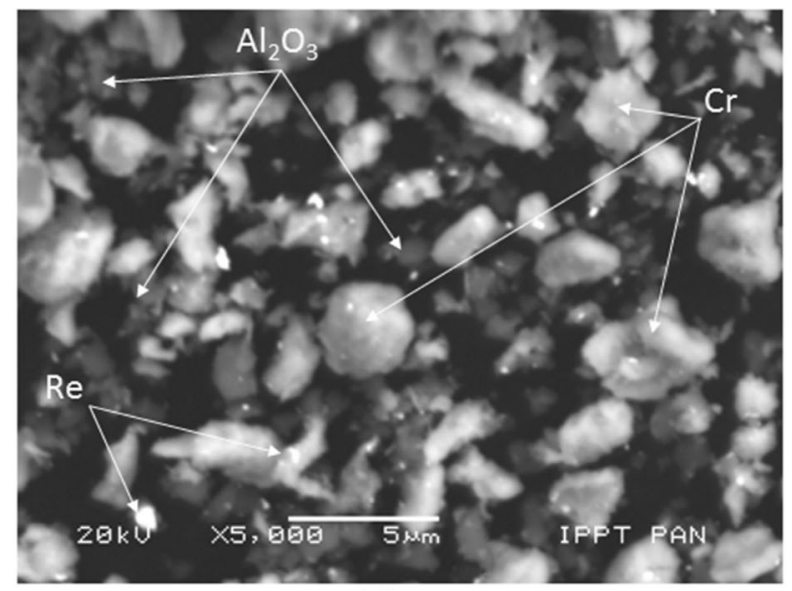

(a)

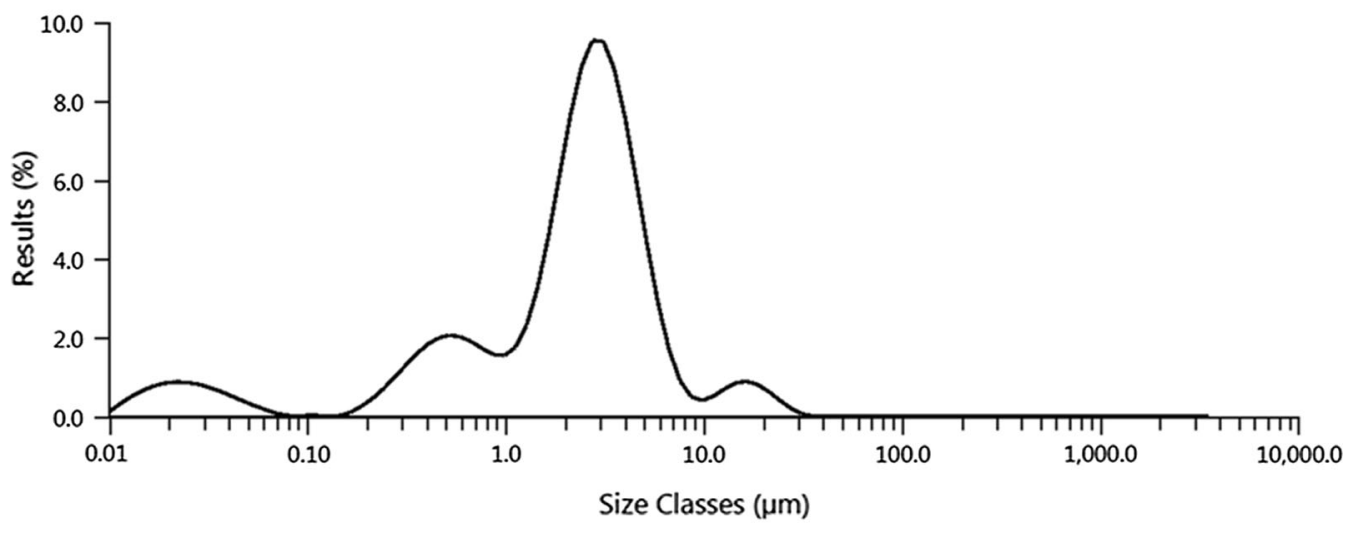

(b)

Fig. 1-Particle size analysis of $\mathrm{Cr} / \mathrm{Al}_{2} \mathrm{O}_{3} /$ Re powder mixture: (a) SEM image of the powder mixture after $4 \mathrm{~h}$ of milling, $(b)$ particle size distribution obtained with Malvern Mastersizer 3000 analyzer. 


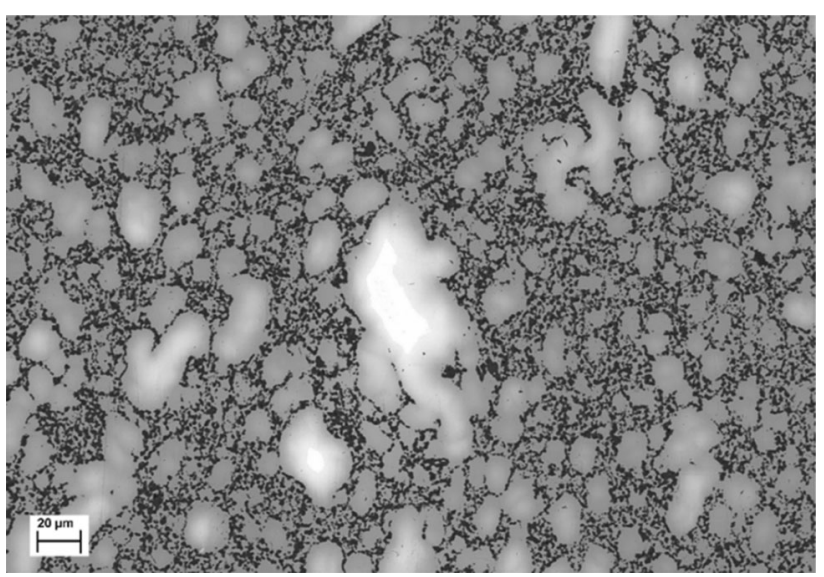

Fig. 2-SEM image of the bulk composite 95 vol pct ( 75 vol pct $\mathrm{Cr} /$ 25 pct vol $\left.\mathrm{Al}_{2} \mathrm{O}_{3}\right)+5$ vol pctRe sintered under pressure (HP). Brighter areas indicate that rhenium is only partially dissolved in the chromium matrix. Sample preparation: OP-S polishing with a colloidal silica suspension with a $\mathrm{pH}$ of 9.8 and a grain size of about $0.04 \mu \mathrm{m}$.

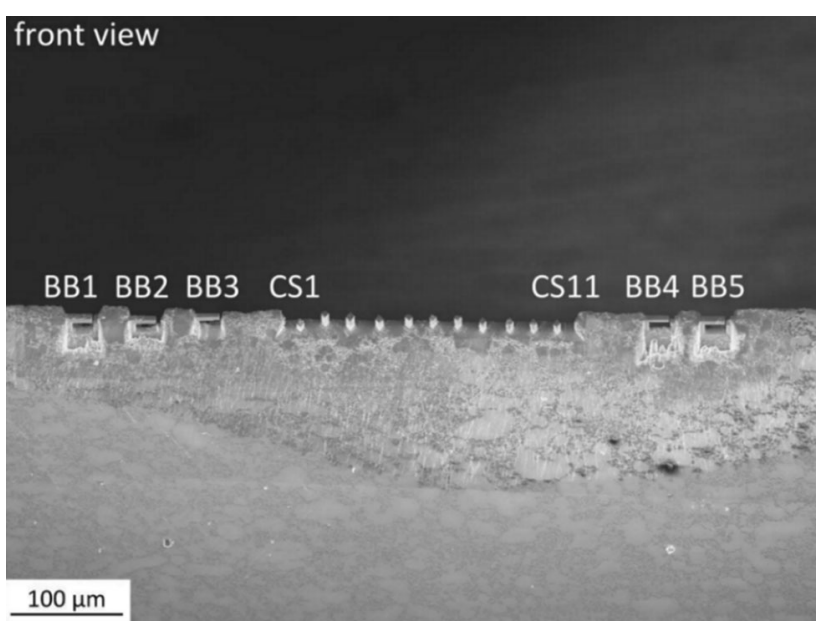

Fig. 3-Overall view of the FIB-milled specimens (BB1 to BB5) used in micromechanical bending experiments. CS1 to CS11 are compression specimens (not considered here).

$30 \mathrm{keV}$ acceleration voltage and a beam current of $2 \mathrm{nA}$ for pre-cutting and $0.6 \mathrm{nA}$ for final cutting. During final cutting, a material layer of about $300 \mathrm{~nm}$ was removed. A series of five specimens labeled as BB1-BB5 were manufactured (Figure 3).

Figure 4 shows five micro specimens $\mathrm{BB} 1$ to BB5, which were FIB milled at different positions from the composite sample to have a wide spectrum of material morphologies in the bending tests. As the material was not homogeneous on the microscale, the composition of each specimen was different, ranging from purely metallic, through small amount of the ceramic phase to large ceramic content. It is to be noted that specimens BB3, BB4 and BB5 (Figures 4(c) through (e)) contain no ceramic particles near the fixed end.

The experiments were performed at Montanuniversität in Leoben (Austria) using a LEO 982 SEM (Zeiss, Oberkochen, Germany) incorporating an UNAT-SEM Indenter (ASMEC, Radeberg, Germany) dedicated for in situ micromechanical testing at high resolution. Using such a setup, the deformation process on the microscale is directly observable during the experiment. The microcantilevers were loaded under displacement control at a constant deformation rate of $1 \mu \mathrm{m} / \mathrm{min}$ by a wedgeshaped conductive diamond tip placed at the end of the beam (see Figure 5 in Section III). The force and displacement data were recorded while testing. For each experiment, several loading-unloading cycles were performed with increasing displacement.

\section{Numerical Simulation and Interface Characterization}

The SEM images of the composite microcantilever selected for the numerical simulation of the bending experiment were obtained in a grid made of $511 \times 121$ pixels. These data were processed by a specific software (Simpleware ScanIP/FE) ${ }^{[25]}$ to identify the spatial distribution of the alumina particles in the chromium(rhenium) matrix and to create a FE mesh. A geometrical model was set up as a thin slice of a representative microstructure with a thickness of one pixel size (about $0.04 \mu \mathrm{m})$ imported within a non-linear finite element code (ABAQUS 6.14, 2014). ${ }^{[26]}$ A model of the laboratory test was realized assuming expansion of the thin slice microstructure in the third direction. Even though the geometrical model can formally be considered as three-dimensional, the performed analyses are plane idealization of the microbending tests.

There are two types of Cohesive Zone Models (CZM) available in the commercial finite element code ABAQUS 6.14, 2014 [26]: (i) Cohesive elements with finite thickness based on a regular continuum stress-strain constitutive behavior, used to model debonding behavior of the boundaries between material constituents when thickness of the interface is considerable, and (ii) Cohesive surface with zero thickness based on a specific traction-separation constitutive behavior, widely used to model debonding behavior when the interface thickness is negligible. In the present study, the morphology of $\mathrm{BB} 2$ and $\mathrm{BB} 1$ specimens is modeled by irregular regions of $\mathrm{Cr}(\mathrm{Re})$ and $\mathrm{Al}_{2} \mathrm{O}_{3}$ with the boundary layers between them being of negligible thickness ( $c f$. Figure 8 in Section IV). Therefore, the cohesive surface with zero thickness and bi-linear traction-separation constitutive equations available in Reference 26 are used. In this approach, no cohesive elements are defined but their cohesive behavior, such as damage initiation and evolution, is defined via a contact interaction across the cohesively connected continuum elements of bulk materials (here: $\mathrm{Cr}(\mathrm{Re})$ and $\mathrm{Al}_{2} \mathrm{O}_{3}$ ). The cohesive characteristics are implemented by the contact master-slave formulation in the finite element code. In this formulation the bulk materials separation is represented through zero thickness of the cohesive surface.

\section{EXPERIMENTAL RESULTS}

It was observed during the conducted bending experiments that deformation and failure of the microcantilevers were contingent upon the composite structure, 

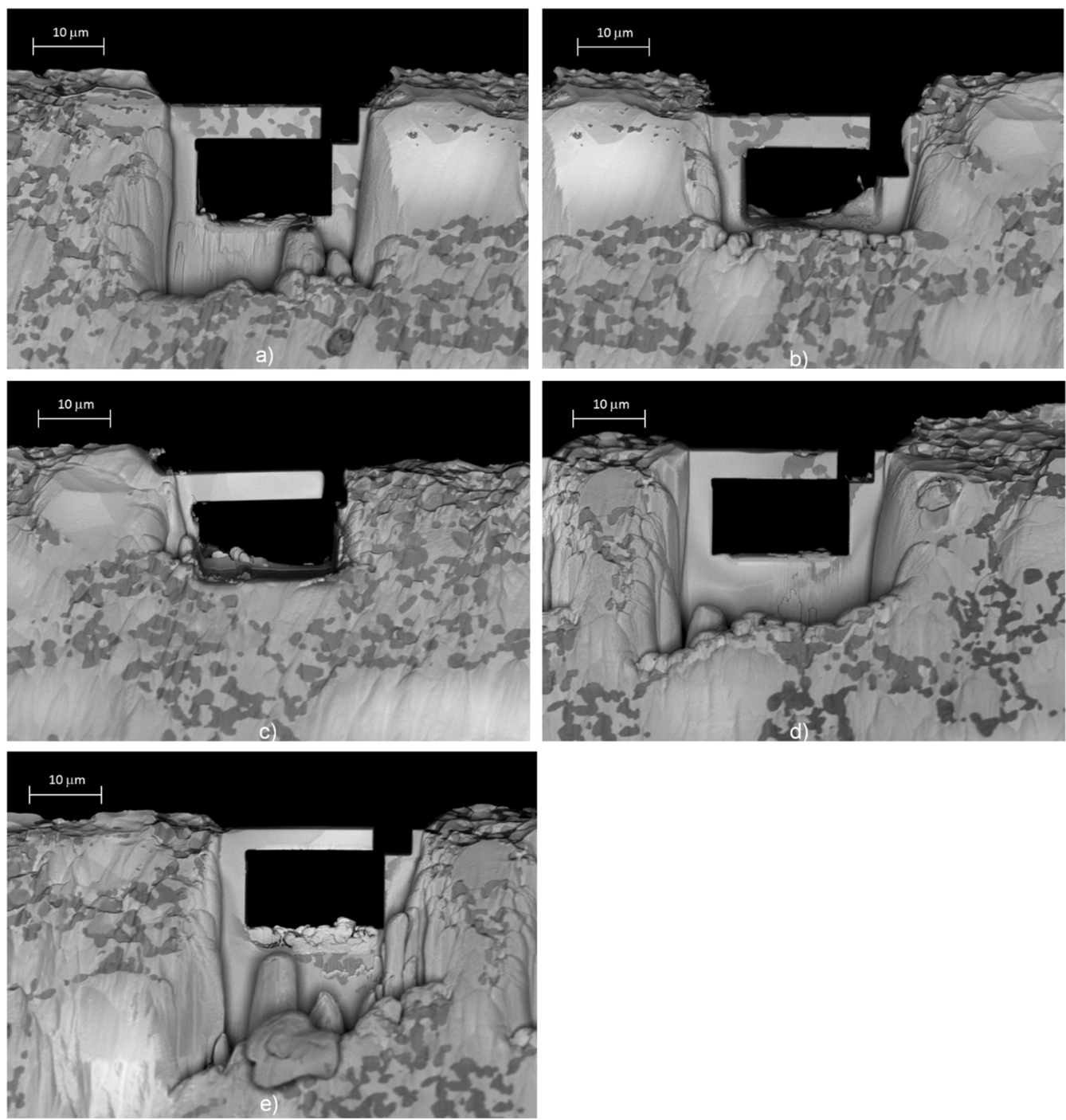

Fig. 4-SEM images of the microcantilevers exhibiting different morphologies: (a) BB1, (b) BB2, (c) BB3, (d) BB4, (e) BB5. Dark regions visible in BB1, BB2 and BB4 specimens are aluminum oxide particles.

especially in the critical cross-sections near the specimens fixed ends. The specimens with low $\mathrm{Al}_{2} \mathrm{O}_{3}$ content did not fracture but deformed plastically (Figure 5(a)), whereas material separation along the $\mathrm{Cr}(\mathrm{Re})-\mathrm{Al}_{2} \mathrm{O}_{3}$ interfaces was detected in the specimens with higher alumina content (Figures 5(b) and (c)).

The load-displacement (or $F-u$ ) curves, where $u$ is the beam deflection in the position where the point load $F$ was applied through the nanoindenter, were recorded in microbending tests and are summarized in Figure 6. Five or six loading-unloading loops were performed in each experiment. The maximum force $\left(F_{\max }\right)$ recorded during bending of microcantilever BB $4(0.66 \mathrm{mN}$, Figure 6(a)), which was free of alumina particles near the specimen's fixed end (Figure 5(a)), was significantly lower than the maximum force sustained by the specimen BB1 (1.71 mN, Figure 6(b)) or BB2 $(2.19 \mathrm{mN}$, Figure 6(c)), which contained alumina particles therein. In MMCs, the type of interface (strong vs weak) between the matrix and reinforcement can affect the overall damage mechanism and the composite strength. ${ }^{[27]} \mathrm{A}$ weak interface would debond at low stresses and prevent the ceramic particle from experiencing the stress and thus prevent strengthening. In the present investigation, the presence of ceramic particles in the critical cross-sections of BB1 and BB2 specimens actually enhanced their bending strength as compared with BB4, which failed by plastic deformation. The observed strengthening in $\mathrm{BB} 1$ and $\mathrm{BB} 2$ is due to the alumina particles responding to the stress that is transmitted through the interface. In addition, it is to be noticed that $F_{\max }$ in the case of BB1 (Figure 6(b)) was lower than $F_{\max }$ for BB2 (Figure 6(c)). These experimental findings and their impact on the assumptions of the numerical model are further discussed in Section V.

It was also observed during the experiment that a brittle crack generated along a $\mathrm{Cr}(\mathrm{Re})-\mathrm{Al}_{2} \mathrm{O}_{3}$ interface in the BB2 specimen (Figure 5(c)) propagated in an uninterrupted manner until the metal part in the specimen's bottom was reached, where the crack was arrested. 


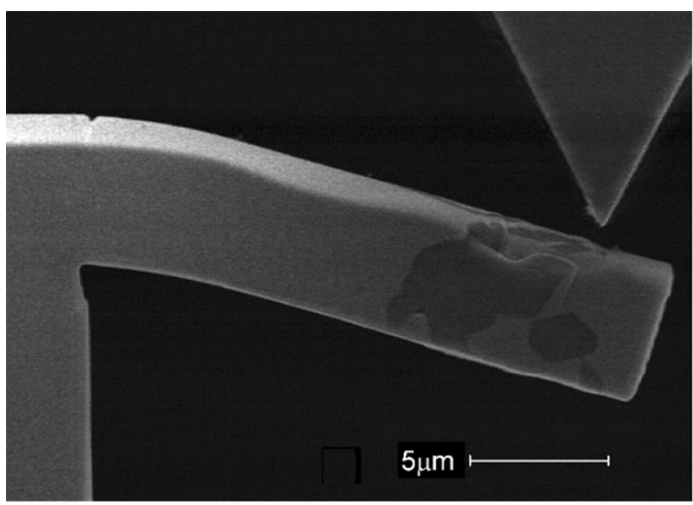

(a)

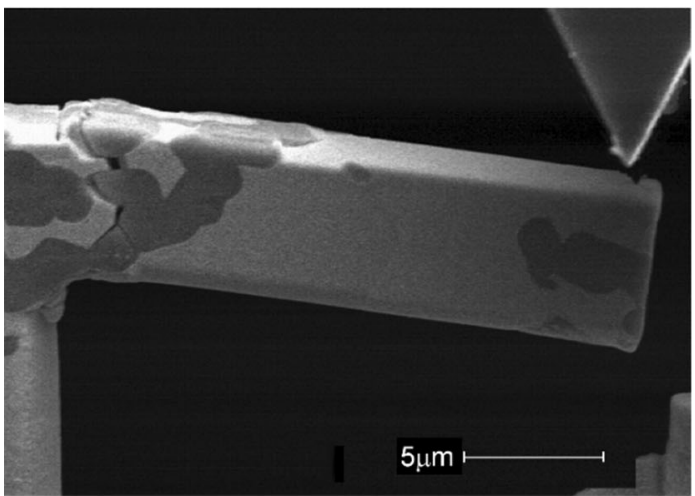

(c)

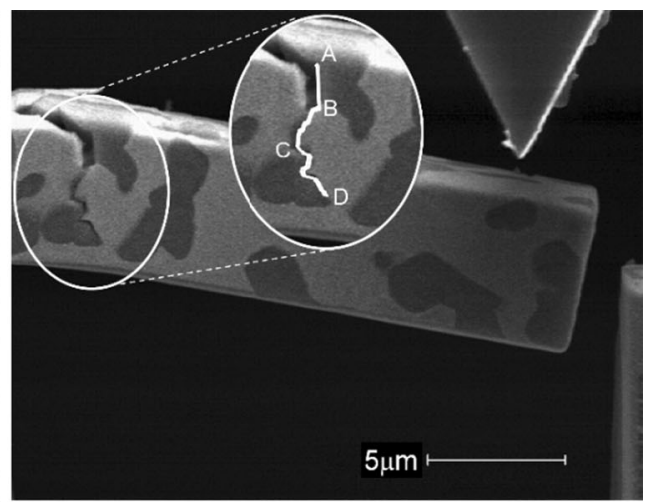

(b)

Fig. 5-Deformation and fracture modes of $\mathrm{Cr}(\mathrm{Re}) / \mathrm{Al}_{2} \mathrm{O}_{3}$ microcantilevers in bending: (a) specimen BB4 experiencing plastic deformation with no fracture; $(b)$ specimen $\mathrm{BB} 1$ and $(c) \mathrm{BB} 2$, both with predominantly brittle fracture along $\mathrm{Cr}(\mathrm{Re})-\mathrm{Al}_{2} \mathrm{O}_{3}$ interfaces. Segments denoted with capital letters in (b) refer to the observed stages of cracking: (i) brittle separation along the first interface (A-B), (ii) matrix cracking between two alumina grains $(\mathrm{B}-\mathrm{C})$ preceded by some plastic deformation of the matrix, and (iii) brittle cracking along the second interface (C-D).

Afterwards, the BB2 specimen continued to deform plastically.

On the other hand, in the BB1 specimen, the crack growth (Figure 5(b)) was a two-step process as observed in situ by the SEM coupled with a fast camera. At the critical load, a brittle crack appeared and propagated along the first segment (A-B) of the $\mathrm{Cr}(\mathrm{Re})-\mathrm{Al}_{2} \mathrm{O}_{3}$ interface, and then it stopped for a while. This corresponds to a small hardening effect in the descending part of the $F-u$ curve ( $c f$. the non-linear segment B-C of the curve in Figure 6(b)) due to plastic deformation of the matrix. In the subsequent loading-unloading loops the crack changed its direction and propagated through the metal matrix until it reached the alumina particle in the bottom part of the specimen, where it resumed to follow along the $\mathrm{Cr}(\mathrm{Re})-\mathrm{Al}_{2} \mathrm{O}_{3}$ interface. From the analysis of the series of photos taken during the experiment it can be inferred that the segment $(\mathrm{C}-\mathrm{D})$ of the curve in Figure 6(b) represents both the crack propagation through the $\mathrm{Cr}(\mathrm{Re})$ matrix and the cracking along the $\mathrm{Cr}(\mathrm{Re})-\mathrm{Al}_{2} \mathrm{O}_{3}$ interface in the bottom part of $\mathrm{BB} 1$ specimen. These matrix and interface cracks appeared practically at the same moment in time. The remaining bottom part of BB1 (light gray region in Figure 5(b)), which was mainly metallic, continued then to deform by plastic flow of the undamaged $\mathrm{Cr}(\mathrm{Re})$ ligaments.
A plausible interpretation of the post-peak response of the BB1 specimen in Figure 6(b) follows from a closer examination of the composite structure vs fracture evolution in Figure 5(b). The segment (A-B) corresponds to brittle separation along the $\mathrm{Cr}(\mathrm{Re})-\mathrm{Al}_{2} \mathrm{O}_{3}$ interface in the upper part of BB1. Then, the crack deviates from this interface and propagates through the metal matrix until the interface in the lower part of the specimen is reached, where it resumes to grow along it in brittle mode (Figure 5(b)). According to the SEM online observation during the experiment, the crack propagation through the matrix and then along the interface is a continuous process. Hence, it is assumed that the almost vertical segment (C-D) of the curve in Figure 6(b) represents jointly these two stages of BB1 specimen's fracture. The local hardening effect $(\mathrm{B}-\mathrm{C})$ in the overall softening part of the $F-u$ curve stems from a small load recovery in the plastic range of matrix deformation that preceded the further crack growth as reflected by the steep force drop (C-D) in Figure 6(b). It is to be noted that this plastic-hardening effect $(\mathrm{B}-\mathrm{C})$ is beyond the scope of the numerical model presented in the following Sections.

Although not central to this study, it is perhaps interesting to compare the bending strength of $\mathrm{Cr}(\mathrm{Re}) /$ $\mathrm{Al}_{2} \mathrm{O}_{3}$ microcantilevers with the bending strength of 


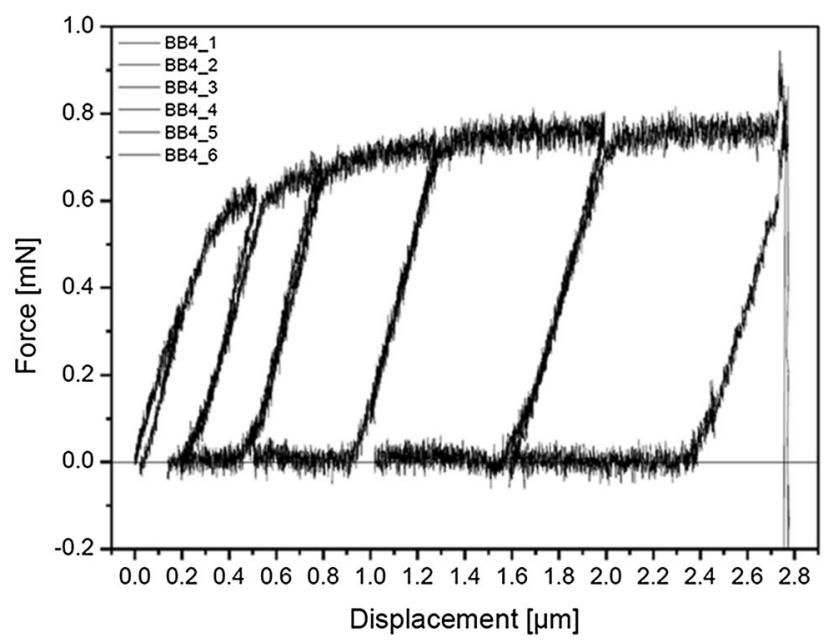

(a)

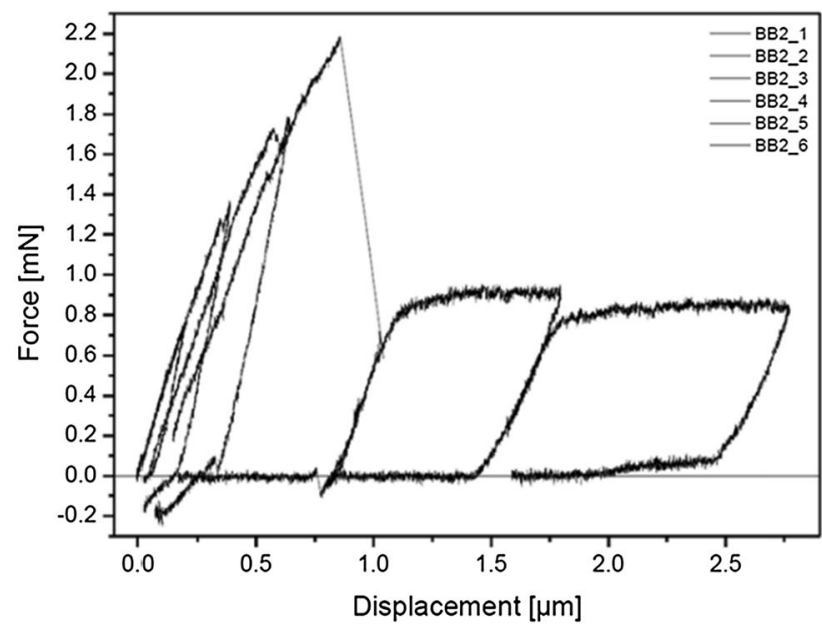

(c)

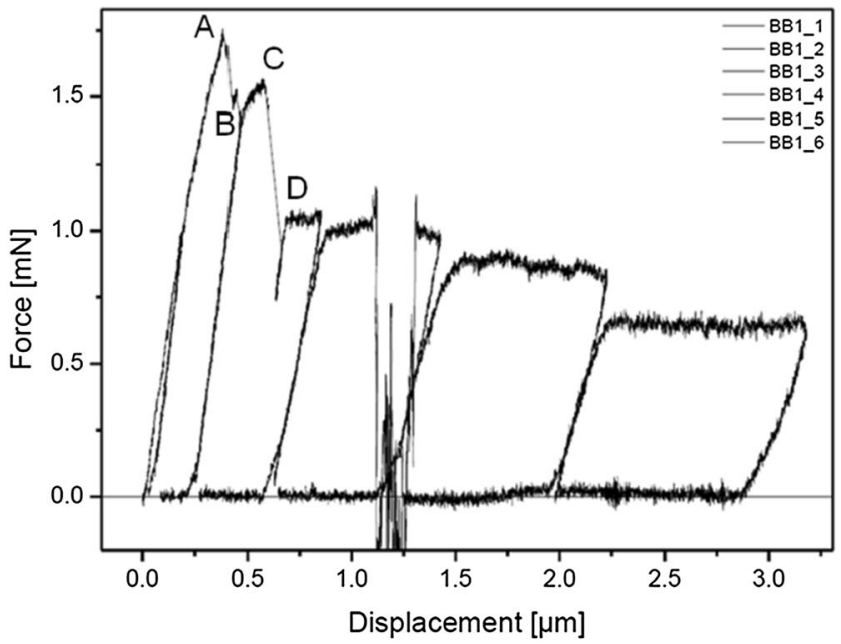

(b)

Fig. 6-Load-displacement curves recorded during microbending tests: $(a)$ specimen BB4 (see Fig. 5(a) for its deformation mode); (b) specimen BB1 ( $c f$. Fig. 5(b)); (c) specimen BB2 ( $c f$. Fig. 5(c)). In (b) segments A-B and C-D correspond to different stages of the crack growth depicted in Fig. 5(b).

macroscopic $\mathrm{Cr}(\mathrm{Re}) / \mathrm{Al}_{2} \mathrm{O}_{3}$ specimens measured in three-point bending (see Reference 28 for details of the measurement procedure and specimens preparation). The average bending strength of $4 \times 4 \times 25 \mathrm{~mm}^{3}$ prismatic specimens obtained from the three-point bending test was $0.65 \mathrm{GPa}$. In the microcantilever tests, the maximum bending stress, calculated at $F_{\max }=1.71$ $\mathrm{mN}$ for $\mathrm{BB} 1$ and $F_{\max }=2.19 \mathrm{mN}$ for BB2, is much higher and equals 1.40 and $2.02 \mathrm{GPa}$ for $\mathrm{BB} 1$ and $\mathrm{BB} 2$, respectively.

The deformation and fracture mode of the BB2 specimen are consistent with an almost uniform through-thickness spatial distribution of the alumina ceramic phase in the chromium(rhenium) matrix at the position where fracture has occurred (indicated by the white ellipse in Figure 7(a)). In the BB1 case, only a fraction of the specimen thickness in the fractured region is occupied by the alumina phase (Figure 7(b)), hence the interface length is smaller than in BB2.
The inserts in Figures 7(a) and (b) depict schematically the crack paths on the upper surfaces of the BB2 and BB1 specimens at the onset of fracture. The white tortuous lines represent real cracks observed in the series of shots under SEM taken during the bending experiments. The crack in BB2 (Figure 7(a) insert) goes through the whole specimen thickness, mainly following the $\mathrm{Cr}(\mathrm{Re})-\mathrm{Al}_{2} \mathrm{O}_{3}$ interfaces and also transecting some alumina grains. For modeling purposes its trajectory on the surface can be approximated by a straight line. The crack on the BB1 upper surface (Figure 7(b) insert) develops along two segments of the interface marked in white, whereas the unreinforced part of the specimen undergoes plastic deformation.

In what follows, the force-displacement curve of microcantilever BB2 (Figure 6(c)) is selected for numerical simulation of the micromechanical bending test, whereas the BB1 curve (Figure 6(b)) is used for model validation. 


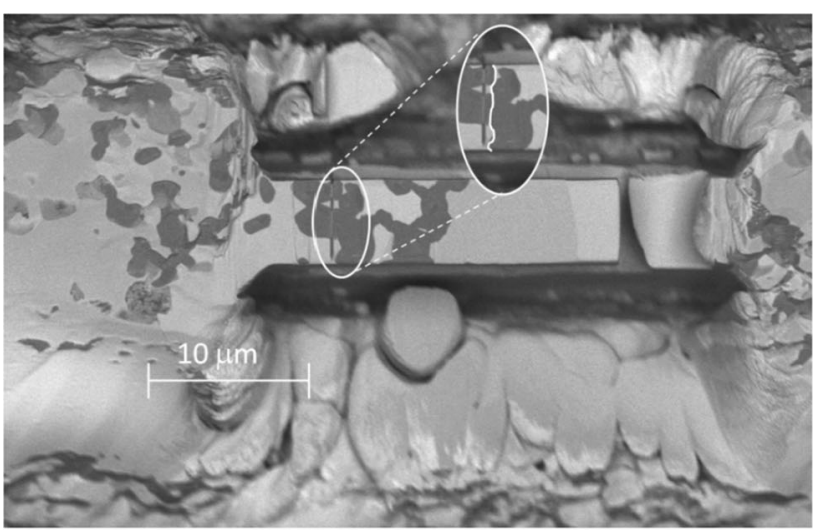

(a)

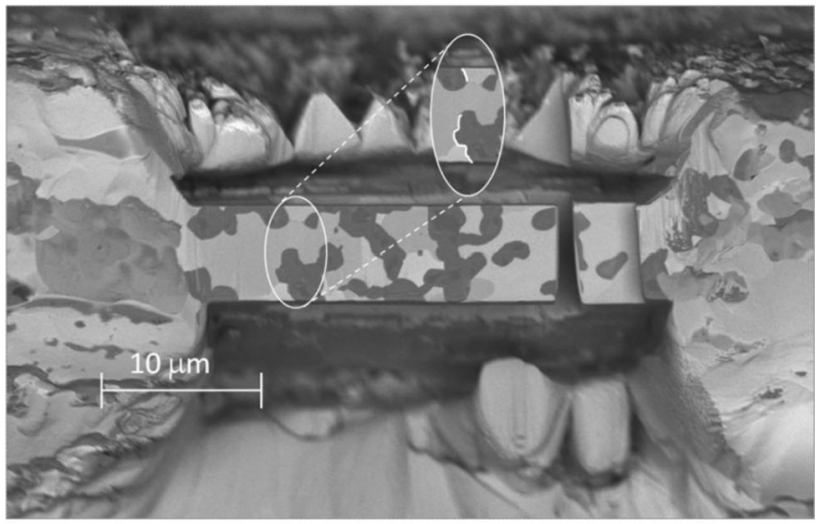

(b)

Fig. 7-SEM micrographs (top views) of micro composite cantilevers showing distribution of alumina particles (dark gray) in the fractured region near specimen's fixed end: (a) BB2, (b) BB1. The inserts depict schematically the crack paths on the upper surfaces of the BB2 and BB1 specimens at the onset of fracture.

\section{MODELING DETAILS}

The chromium(rhenium) and alumina distributions in the specimen $\mathrm{BB} 2$ and $\mathrm{BB} 1$ are visualized in gray scale in Figures 8(a) and (b). The microstructure of BB2 cantilever is reproduced in the numerical model by a thin slice of the solid, 1 pixel (about $0.04 \mu \mathrm{m}$ ) thick, discretized by linear tetrahedral elements. Inspired by the actual BB2 composite microstructure (Figures 5(c) and 7(a)), it is assumed that the microstructure depicted in Figure 8(a) does not change in the direction perpendicular to the slice plane. In terms of the boundary conditions this assumption is implemented by blocking the displacements in that direction. Unlike the BB2 specimen, in BB1 the ceramic phase is not present across the whole specimen thickness in the fractured region (see Figure 7(b)). This experimental fact will be taken into account in the numerical simulation of the $\mathrm{BB} 1$ behavior depicted in Figure 6(b).

The considered specimens BB2 and BB1 exhibit quasi-brittle failure. Thus, isotropic linear elasticity and perfect continuity of the displacement field across the elements is generally assumed, while zero-thickness interface elements endowed with a cohesive traction-separation law are inserted at the interfaces evidenced in Figures 8(a) and (b), where material separation was essentially observed during the microbending experiments.

The elastic constants of chromium(rhenium) matrix and alumina reinforcement used in the numerical simulations are listed in Table I. The Young moduli of chromium(rhenium) and alumina phases were measured by nanoindentation conducted directly on the composite samples using NanoTest Vantage $\AA$ system produced by MicroMaterials Laboratory MML. The experiments were conducted using a Berkovich-shaped diamond indenter and applying a $20 \mathrm{mN}$ load. The indentation

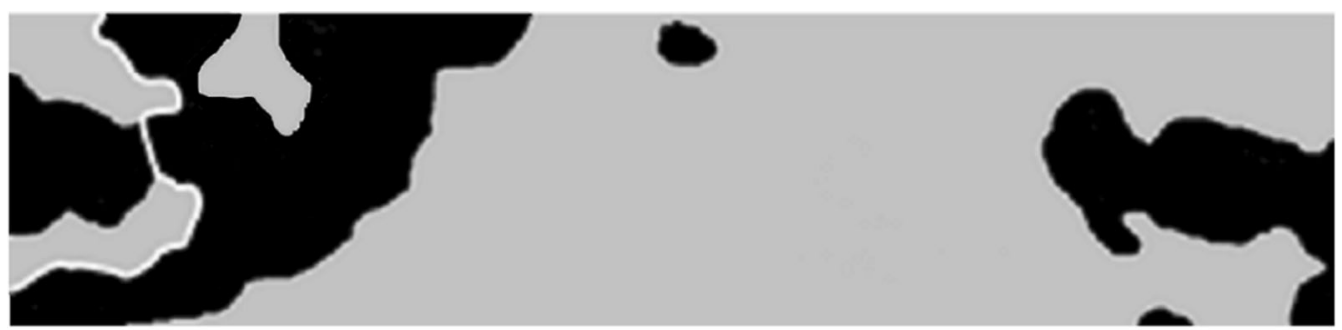

(a)

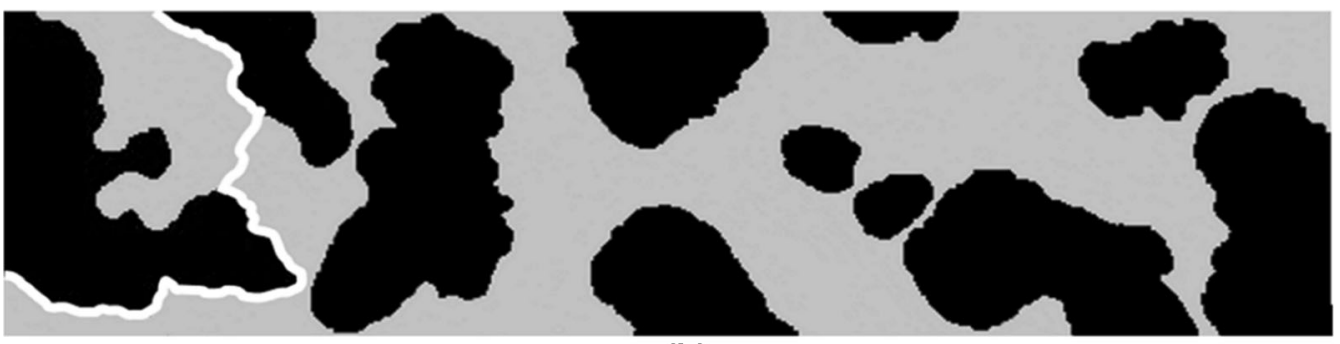

(b)

Fig. 8-Reconstructed structure of the composite microcantilevers selected for numerical simulations: (a) BB2, (b) BB1. Gray color denotes $\mathrm{Cr}(\mathrm{Re})$ matrix, black corresponds to $\mathrm{Al}_{2} \mathrm{O}_{3}$ reinforcing phase. Interfaces along the fracture paths modeled by cohesive elements are marked in white. 
depth was $350 \mathrm{~nm}$ for the metallic matrix and $300 \mathrm{~nm}$ for the ceramic-reinforcing phase. The values of Poisson's ratio for chromium and alumina were taken from References 29 and 30, respectively.

\section{A. Cohesive Model}

The progressive separation process that occurs at the chromium(rhenium)-alumina interfaces represented in Figures $8(\mathrm{a})$ and (b) is simulated by a cohesive model. It relates the traction components $T_{n}, T_{s}$, and $T_{t}$ to the displacement discontinuities $\delta_{n}, \delta_{s}$, and $\delta_{t} . T_{n}$ is perpendicular to the considered interface, while $T_{s}$ and $T_{t}$ act in directions tangential to the interface in the planes shown in Figures 6(a) and (b) and out of those planes, respectively. Analogously, $\delta_{n}$ represents the opening displacement, while $\delta_{s}$ and $\delta_{t}$ denote the sliding components.

The variables relevant for the present application are $\left(T_{n}, T_{s}, T_{t}\right)$ and $\left(\delta_{n}, \delta_{s}, \delta_{t}\right)$. The assumed relationships between these traction components and the discontinuities in Mode I and Mode II are visualized in Figures 9(a) and (b). Mode III can be described using the same traction-separation relation as for Mode II (Figure 9(b)) upon replacing the subscript $s$ with $t$. The

Table I. Elastic Constants of Chromium(Rhenium) and $\alpha$-Alumina Used in the Numerical Model

\begin{tabular}{lcc}
\hline Material & $\begin{array}{c}\text { Elastic Modulus } \\
(\mathrm{GPa})\end{array}$ & $\begin{array}{c}\text { Poisson } \\
\text { Ratio }\end{array}$ \\
\hline Chromium(Rhenium) & 270 & 0.2 \\
Alumina & 357 & 0.21 \\
\hline
\end{tabular}

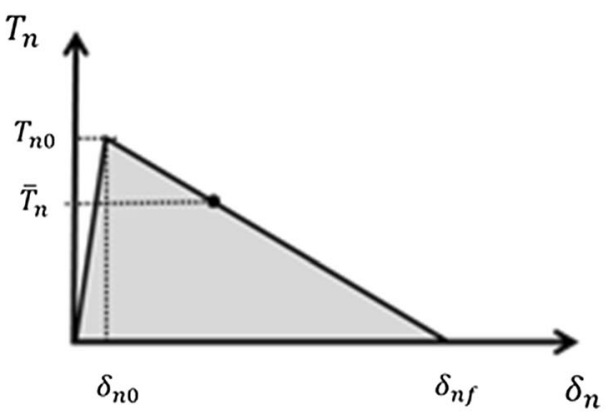

(a) initial branches in the graphs in Figure 9 define the elastic compliance of the interface. In the present application, the slope $K=T_{n 0} / \delta_{n 0}=T_{s 0} / \delta_{s 0}=T_{t 0} / \delta_{t 0}$ is set equal to a large value $\left(10^{8} \mathrm{GPa} / \mathrm{m}\right)$ to reproduce the initial continuity of the undamaged material without compromising the numerical stability. The cohesive model is thus characterized by the independent interfacial strength values $T_{n 0}, T_{s 0}, T_{t 0}$ and by a common fracture energy value, $G_{c}$, which represents the specific energy dissipated in the separation process and corresponds to the area under the traction-separation curves in pure opening or sliding mode (gray areas in Figure 9).

In the opening mode damage initiates when $T_{n}=T_{n 0}$ and evolves with $\delta$ according to the linear damage evolution law Eq. [1], proposed in References 31 and 32 The residual interfacial strength is progressively reduced to $\bar{T}_{n}=\left(1-D_{n}\right) T_{n 0}$. It can be quantified by computing the gradually increasing damage variable $D_{n}$, which is related to the maximum relative displacement at the material separation surface as ${ }^{[31]}$ :

$$
D_{n}=\frac{\delta_{n f}\left(\delta_{n \max }-\delta_{n 0}\right)}{\delta_{n \max }\left(\delta_{n f}-\delta_{n 0}\right)}, \quad D_{n} \in[0,1]
$$

In Eq. [1], the displacements $\delta_{n 0}, \delta_{n f}$ are defined in Figure 9, while $\delta_{n \max }$ stands for the maximum relative displacement in Mode I recorded at a contact point during the loading history. When $\delta_{n} \geq \delta_{n f}, D_{n}=1$ and $\bar{T}_{n}=0$ indicating that the cohesive surface is fully detached from the bulk materials.

In the present study a mixed-mode can be expected for a complex interfacial debonding between the two dissimilar materials of which the $\mathrm{Cr}(\mathrm{Re}) / \mathrm{Al}_{2} \mathrm{O}_{3} \mathrm{MMC}$ is composed. Hence, the traction-separation constitutive law for mixed-mode can be defined as shown in Figure 10.

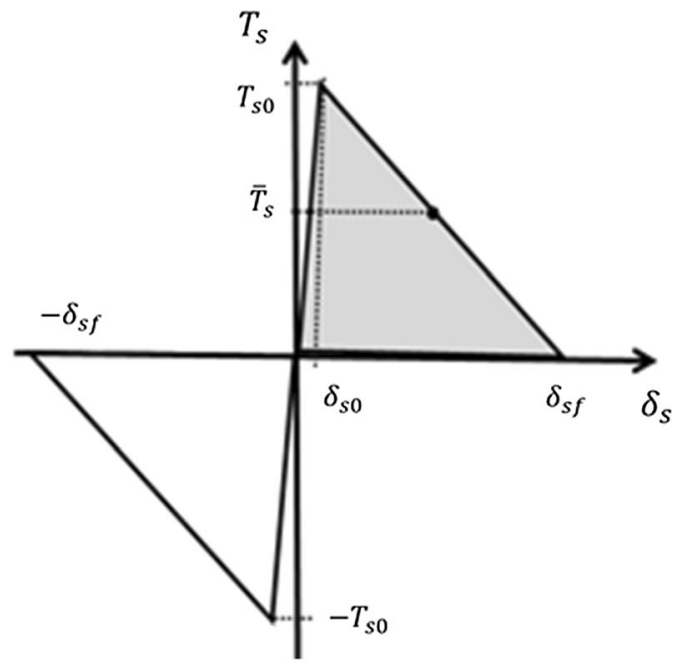

(b)

Fig. 9-Schematic of the bilinear traction vs separation law assumed in the simulations: $(a)$ pure opening (Mode I), and (b) pure sliding (Mode II). Notation used: $\delta_{n 0}, \delta_{s 0}$ are initial separation displacements at the contact point corresponding to Mode I and II, respectively; $\delta_{n f}, \delta_{s f}$ are the respective final displacements corresponding to complete decohesion. 


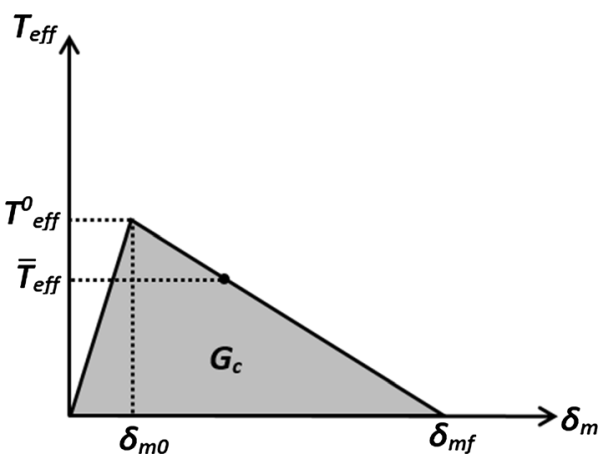

Fig. 10-Schematic of the bilinear effective traction $\left(T_{\text {eff }}=\right.$ $\left.\sqrt{T_{n}^{2}+T_{s}^{2}+T_{t}^{2}}\right)$ and separation $\left(\delta_{m}=\sqrt{\delta_{n}^{2}+\delta_{t}^{2}+\delta_{s}^{2}}\right)$ representation of the mixed-mode. ${ }^{[26,31]}$

In the mixed-mode damage initiates when the effective traction $T_{\text {eff }}$ reaches a critical value $T_{\text {eff }}^{0}$. The interfacial residual strength is progressively reduced to $\bar{T}_{\text {eff }}=\left(1-D\left(\delta_{m}\right)\right) T_{\text {eff }}^{0}$. The damage variable $0 \leq$ $D\left(\delta_{m}\right) \leq 1$ depends on the effective relative separation displacement $\left(\delta_{m}\right)$, combining the normal $\left(\delta_{n}\right)$ and the sliding separations $\left(\delta_{s}, \delta_{t}\right)$ across the interface, according to the following expression ${ }^{[26,31]}$.

$$
D\left(\delta_{m}\right)=\frac{\delta_{m f}\left(\delta_{m \max }-\delta_{m 0}\right)}{\delta_{m \max }\left(\delta_{m f}-\delta_{m 0}\right)} \quad D \in[0,1],
$$

In Eq. [2] $\delta_{m f}$ refers to the effective separation at complete decohesion, $\delta_{m 0}$ denotes the effective separation at the damage initiation, and $\delta_{m \max }$ represents the maximum value of the effective separation attained during the loading history. When $\delta_{m} \geq \delta_{m}, D\left(\delta_{m}\right)=1$ and $\bar{T}_{\text {eff }}=0$ indicating that the cohesive surface is fully fractured.

As it was already stated at the beginning of this Section, the proposed numerical model is based on a planar idealization of the microbending tests. As a result, even if admitted in the simulations, Mode III will not be activated due to the applied lateral constraints. In what follows, in the notation referring to the mixedmode the traction $T_{s 0}$ is thus omitted.

\section{NUMERICAL RESULTS AND DISCUSSION}

Recent studies in micromechanics have shown that simulating debonding mechanisms and predicting interfacial properties are widely analyzed for periodic and random microstructures with regular interfaces. ${ }^{[33-35]}$ Moreover, the same problem was studied on a classical example of debonding in double cantilever beam bending. ${ }^{[32,36]}$ It is noticeable that the problem of determining interfacial properties on irregular interface boundaries has rarely been tackled by modeling. This is mostly due to complexity in representing real microstructures with irregular interface boundaries and difficulties with characterizing the cohesive behavior of interface.

\section{A. Identification of Interfacial Failure Properties}

The interface properties that match the microcantilever test results are identified by an extensive parametric study. Examples of the numerical output that can be obtained with different sets of failure parameters are shown in Figure 11. The simulation results are compared to the force-displacement curves obtained in the initial phases of the microbending experiments. The graphs summarize the sample response from the situation of perfect adhesion between the chromium(rhenium) matrix and alumina reinforcement to separation at the chromium(rhenium)-alumina interface, which are represented by the ascending branch and by the post-peak softening branch of the curves, respectively.

In the above simulations, the microcantilevers were discretized with four-nodded linear tetrahedron elements with an optimal element size of $0.041 \mu \mathrm{m}$. This size of the element was established based on the convergence rate of strain energy of the models corresponding to different element sizes. To check if the results of the load-displacement simulations for BB2 (Figure 11) are independent of the mesh size, the FEM calculations were performed using three different mesh sizes $(0.033,0.041,0.051 \mu \mathrm{m})$ to discretize the specimen's microstructure obtained from the SEM images. The mesh-sensitivity analysis (Figure 12) indicates that the obtained results can be treated as mesh-independent. The selected element size of $0.041 \mu \mathrm{m}$ is optimal as it gives accurate predictions at a relatively low computational effort.

The graphs in Figures 11(a) through (d) show that this experimental output can be matched with almost the same accuracy by different combinations of the parameter values. Thus, identification of the interface properties requires further information, represented by the actual fracture mode of the investigated sample.

It should be noted that in the mixed-mode (Figure 11(b)) the best fit with the experimental force-displacement curve in the hardening regime was obtained for the interface cohesive strength $0.63 \mathrm{GPa}$. This is much less than the same interface strength $1.3 \mathrm{GPa}$ assumed in the opening mode (Figure 11(c)), which also gives a good match with the experimental data. In both cases a common value of the fracture energy $G_{c}=50 \mathrm{~J} / \mathrm{m}^{2}$ was assumed to achieve the best fit with the experimental response. The SEM images of $\mathrm{BB} 1$ and $\mathrm{BB} 2$ microstructure (Figures 5(b) and (c)) and their representation in numerical simulations (Figures 8(a) and (b)) suggest that the cohesive strength and the fracture energy should be sought under the assumption of mixed-mode loading conditions. This assumption leads to a steep descending branch in the load-displacement curve of Figure 11(b) (red line), which is close to the experimental output and reflects the brittleness of the fracture process. The best fits in Mode I calculations (red curves in Figures 11(c) and (d)) overestimate the cohesive strength predicted in the mixed-mode ( $c f$. red curves in Figures 11(a) and (b)) almost by a factor of 2 . 


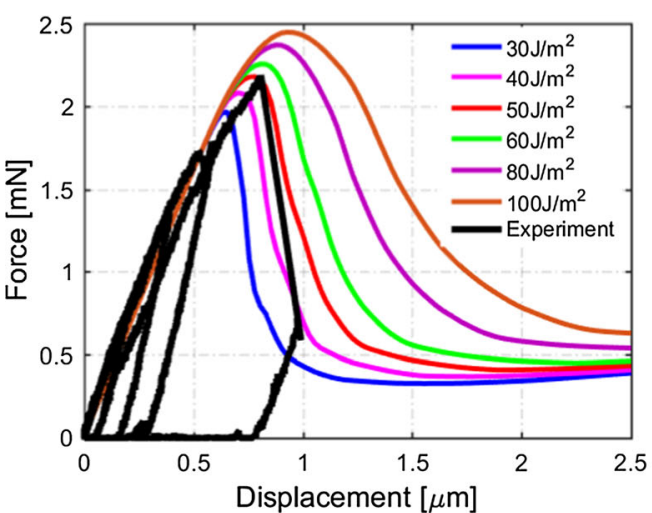

(a)

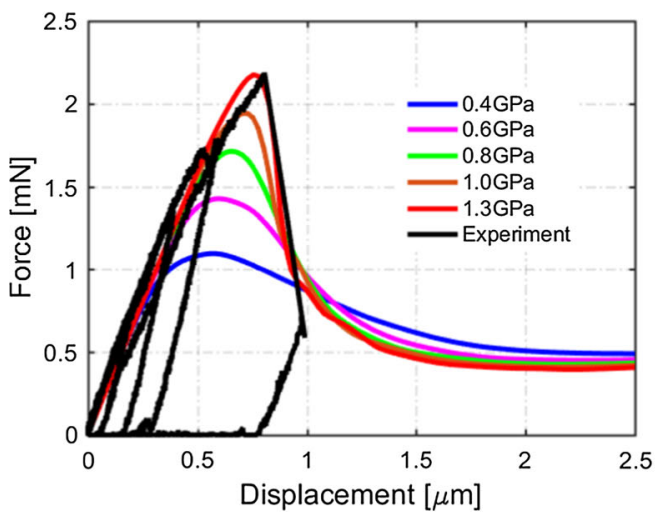

(c)

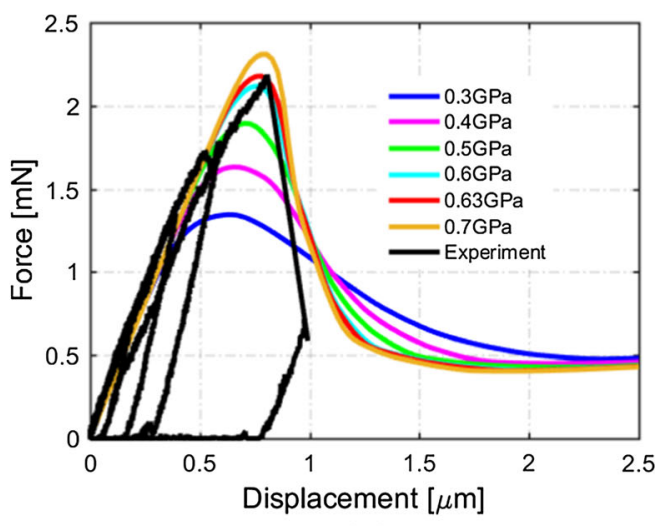

(b)

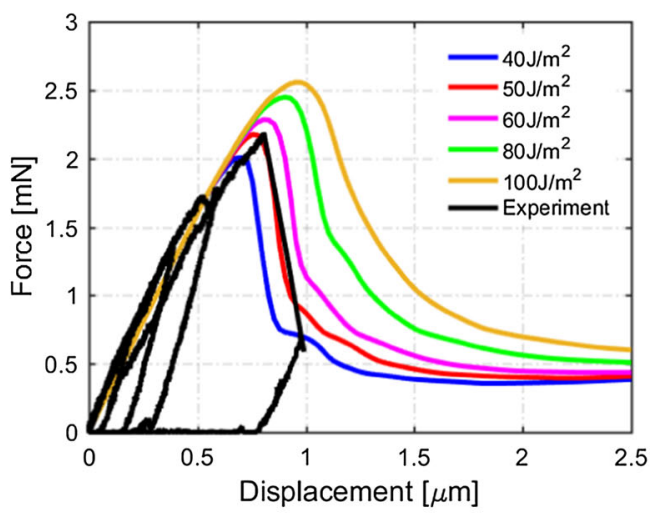

(d)

Fig. 11-Load displacement curves for the $\mathrm{Cr}(\mathrm{Re}) / \mathrm{Al}_{2} \mathrm{O}_{3}$ specimen $\mathrm{BB} 2$ obtained from the numerical computations, by assuming: $(a) T_{n 0}=$ $T_{s 0}=0.63 \mathrm{GPa}$ and different values of fracture energy $G_{c} ;(b) G_{c}=50 \mathrm{~J} / \mathrm{m}^{2}$ and different values of $T_{n 0}=T_{s 0} ;(c) G_{c}=50 \mathrm{~J} / \mathrm{m}^{2}, T_{s 0} \mathrm{null}$ and different values of $T_{n 0} ;(d) T_{n 0}=1.3 \mathrm{GPa}, T_{s 0}$ null and different values of fracture energy $G_{c}$ (Color figure online).

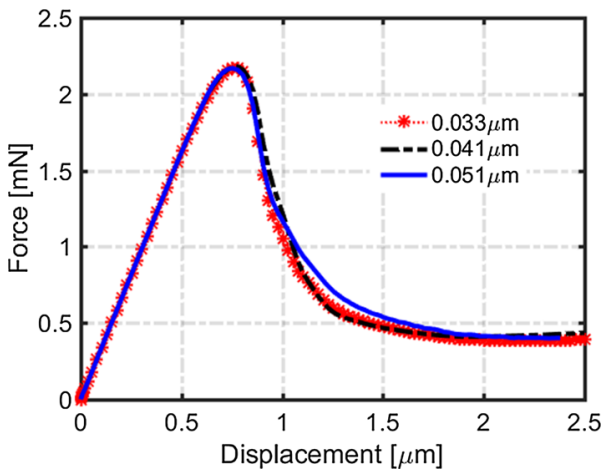

Fig. 12-Mesh-sensitivity analysis of the results for BB2 specimen (Color figure online).

In the mixed-mode simulations giving the best fit with the experimental curves (Figures 11(a) and (b)) it was assumed that the cohesive strengths in tangential and normal directions were equal (i.e. $T_{s 0} / T_{n 0}=1$ ). A legitimate question arises how sensitive are the computed $F-u$ curves to different $T_{s 0} / T_{n 0}$ ratios? Figure 13 shows the force $v s$ displacement response corresponding to different ratios of the cohesive strength in the tangential to normal direction. It is found that the computed global response increases with the increasing $T_{s 0} / T_{n 0}$.

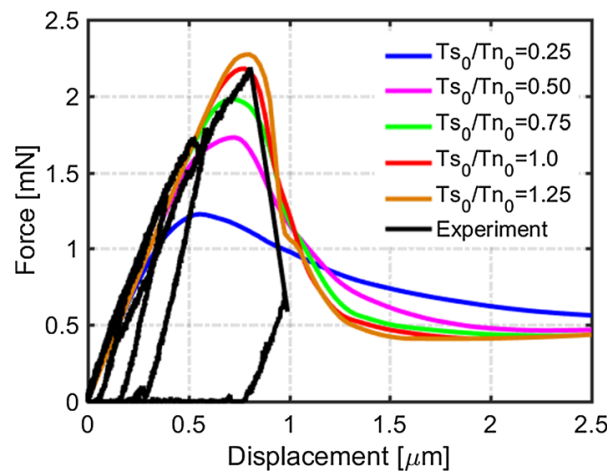

Fig. 13-Numerical force-displacement curves at different values of the cohesive strength ratio $T_{s 0} / T_{n 0}$ (Color figure online).

When this ratio is less than 1 the numerical curves underestimate the peak force. It is also noted that when this ratio is equal to 1 (the red curve) the predicted numerical response is closer to the experimental one. Further increase of this ratio leads to a higher force at the apex as compared with the experimental value. Consequently, the assumption $T_{s 0}=T_{n 0}$ seems to be justified.

However, to ensure that the interface properties $T_{n 0}=$ $T_{s 0}=0.63 \mathrm{GPa}$ and $G_{c}=50 \mathrm{~J} / \mathrm{m}^{2}$ identified from the 
numerical simulations of the BB2 bending experiment are close to physical reality, it is necessary to check how they perform in simulations of the deformation and fracture of the BB1 specimen. This point is addressed in the subsection VB.

Figures 14(a) and (b) visualize the deformation mode and the damage distribution at the interfaces obtained by the simulation of the bending test assuming $T_{n 0}=$ $T_{s 0}=0.63 \mathrm{GPa}$ and $G_{c}=50 \mathrm{~J} / \mathrm{m}^{2}$. Figure $14(\mathrm{a})$ refers to the softening phase (load reduction) caused by cracking at about $1 \mu \mathrm{m}$ overall deflection of the sample before unloading, while Figure 14(b) corresponds to approx. $2 \mu \mathrm{m}$ overall deflection.

From the local deformation and damage distribution in the cantilever, it is difficult to identify the dominant mode of interface behavior due to the presence of complex interfacial boundary region. The comparison between the simulation results and the physical observations evidences that besides the pronounced
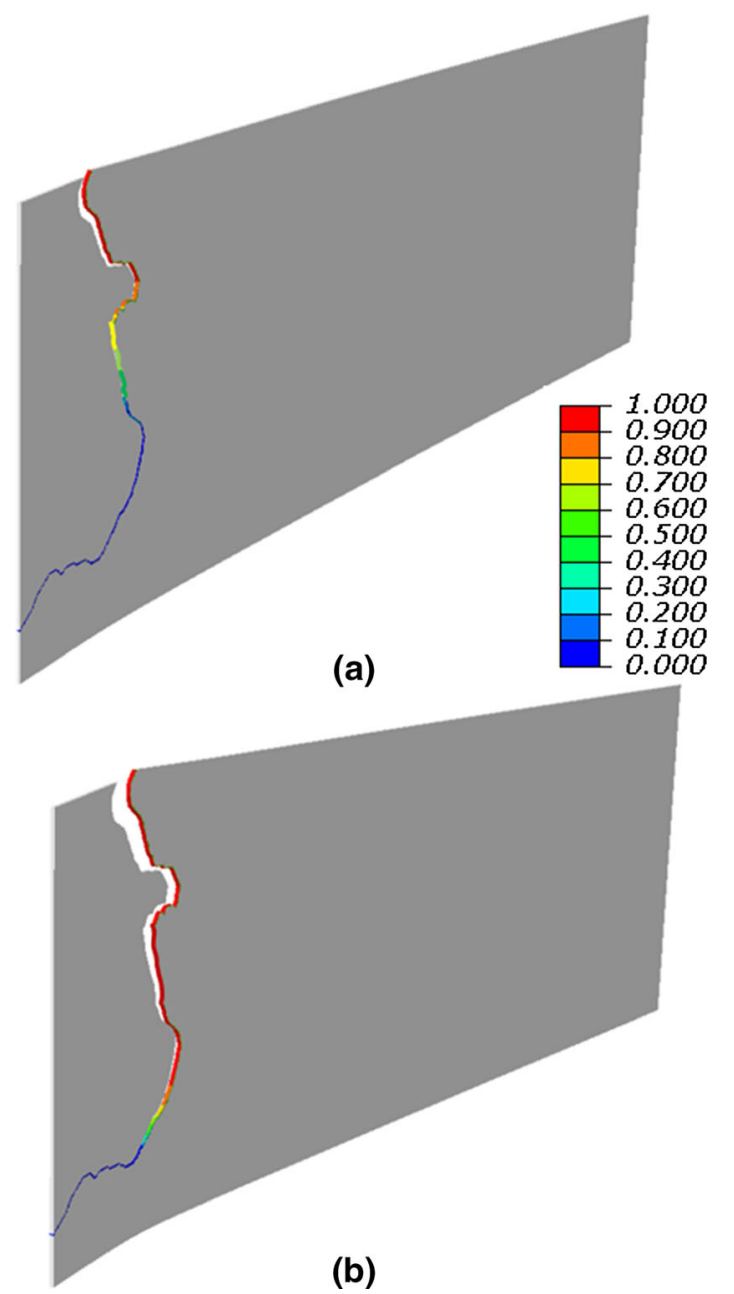

Fig. 14-Deformed shape and damage distribution at the metal-ceramic interfaces of $\mathrm{BB} 2$ specimen at about $1 \mu \mathrm{m}(a)$, and $2 \mu \mathrm{m}(b)$ of the overall specimen deflection. Simulation results are obtained by assuming $T_{n 0}=T_{s 0}=0.63 \mathrm{GPa}$ and $G_{c}=50 \mathrm{~J} / \mathrm{m}^{2}$. The color scale refers to the damage variable $D$ calculated from Eq. [2], where red $(D=1)$ denotes completely damaged (separated) interface and dark blue $(D=0)$ corresponds to intact interface (Color figure online). displacements in the normal direction there is a poor adhesion between the metal and ceramic phase of this composite in other directions. As a consequence, material separation follows a tortuous path as shown in Figure 14.

\section{B. Model Validation}

Numerical simulations of the force-displacement curve for the BB2 microcantilever presented in the preceding subsection have enabled estimation of the in situ values of the cohesive strength and fracture energy of the chromium(rhenium)-alumina interface. Since the starting materials and the composite fabrication conditions were identical for all the microcantilevers tested, the predicted values of the interfacial failure properties for $\mathrm{BB} 2$ (cohesive strength $=0.63$ $\mathrm{GPa}$, fracture energy $G_{\mathrm{c}}=50 \mathrm{~J} / \mathrm{m}^{2}$ ) should work for the BB1 specimen as well. Consequently, a simple validation check of the proposed computational model is to examine whether it predicts the measured values of the maximum force and the corresponding displacement for the BB1 cantilever (Figure 6(b)) with an acceptable accuracy.

Similarly as in the BB2 case, the finite element mesh is obtained from the SEM micrographs of the BB1 microstructure (see Figure 8(b)) by means of the ScanIP/FE software. ${ }^{[25]}$ An imperfect interface is assumed along the crack path disclosed by the SEM images (see Figure 8(b)), whereas all other interfaces remained undamaged throughout the deformation process.

As was already mentioned in Section III, the maximum bending forces $F_{\max }$ sustained by the specimens BB1 and BB2 (Figures 6(b) and (c)) seem to be directly related to the amount and spatial distribution of alumina particles in the vicinity of specimen's fixed end (see Figures 7(a) and (b)). In other words, strong chromium(rhenium)-alumina interfaces enhance the load-bearing capacity of the microcantilever beams. In the case of BB1, the load at the onset of fracture (Figure 6(b)) was significantly lower than in the BB2 case (Figure 6(c)). This is in tune with the lower amount of alumina phase detected across the BB1 thickness in the region where fracture had occurred. In numerical simulations of the BB2 behavior it was assumed that the microstructure of the thin slice (Figure 8(a)) does not change in the direction perpendicular to the slice plane. This assumption was made upon examining the top view of BB2 (Figure 7(a)) which shows an almost continuous presence of the alumina phase across the specimen thickness in the fractured region. In consequence, the projected length of the interface separated by brittle cracking in the BB2 cantilever is equal to the specimen thickness (Figure 7(a) insert). However, if the same assumption is made for the BB1 specimen, then a reduction factor should be introduced in the numerical simulations to account for the fact that the projected total length of the fractured interface occupies 64 pct of the specimen thickness (Figure 7(b) insert).

The interface failure parameters indentified by the sensitivity analysis in the $\mathrm{BB} 2$ case, i.e. $T_{n 0}=T_{s 0}=$ 


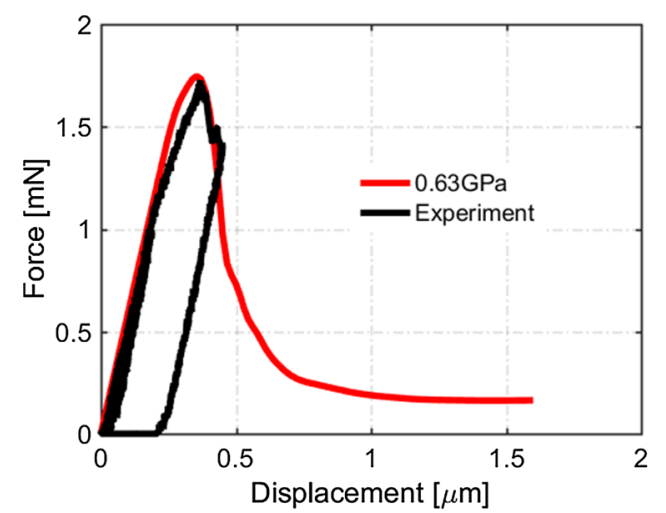

(a)

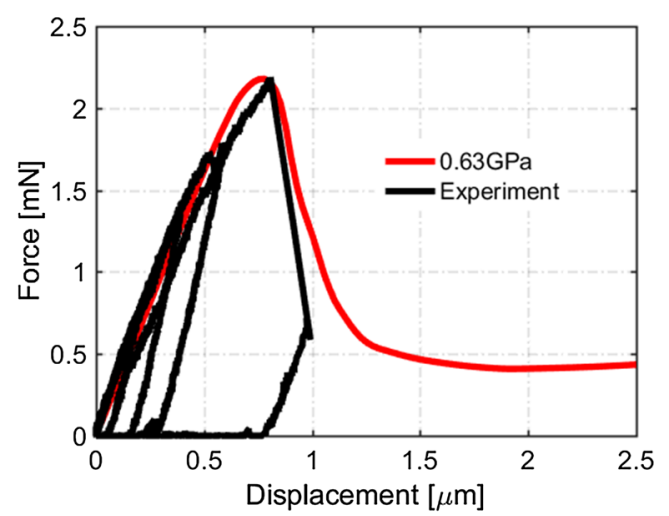

(b)

Fig. 15-Experimental $v s$ numerical $F-u$ curves computed using the interface failure properties $T_{n 0}=T_{s 0}=0.63 \mathrm{GPa}$ and $G_{\mathrm{c}}=50 \mathrm{~J} / \mathrm{m}^{2}$ for specimen: (a) BB1; (b) BB2. A reducing factor of 0.64 is used in computations for $\mathrm{BB} 1$ to account for the smaller total length of interfaces in the fractured region as compared with the BB2 cantilever (see inserts in Figs. 7(a) and (b)).

$0.63 \mathrm{GPa}$ and $G_{\mathrm{c}}=50 \mathrm{~J} / \mathrm{m}^{2}$ are now used to simulate the BB1 deformation and fracture. Upon introduction of the reduction factor $(0.64)$ for the reasons explained above the outcome of numerical simulation of the BB1behavior is as shown in Figure 15(a).

It can be seen from Figures 15(a) and (b) that using the interfacial properties identified by the extensive sensitivity analysis (see Figure 11), the experimental $F-u$ curves obtained from the microbending tests can be reproduced by the cohesive model with a satisfactory accuracy. Consequently, the proposed reverse analysis of the micromechanical bending test results by means of the FEM simulations, taking into account the actual composite microstructure, can be an effective tool for determining the in situ failure properties of the interfaces in MMCs, which are otherwise difficult to measure. However, one should be aware of the limitations of the proposed model, such as the assumed self-similarity of the composite morphology across the specimen thickness. This assumption could be released in the future if $\mathrm{X}$-ray microcomputed tomography is integrated in the experimental setup of a micromechanical test. ${ }^{[37]}$

\section{CONCLUSION}

Miniaturized cantilevers, prepared by FIB milling from a chromium(rhenium)/alumina composite sample fabricated by powder metallurgy, were loaded in bending by a nanoindenter. The force-displacement curves were recorded up to the final fracture. The fracture mode observed in experiments depended on the amount of alumina and the geometry of the $\mathrm{Cr}(\mathrm{Re})-\mathrm{Al}_{2} \mathrm{O}_{3}$ interfacial surfaces in the critical cross-sections near the specimen's fixed end.

A finite element model of the microbending experiment was developed taking into account the reconstructed composite microstructure obtained from the SEM images by a specific software and assuming a bilinear cohesive law for the chromium(rhenium)-alumina interface in mixed-mode loading. The geometrical model, which is a planar idealization of the cantilever bending test, was imported within a non-linear finite element code. Cohesive interfaces were introduced to reproduce the observed material separation processes.

The following conclusions can be drawn from the performed simulations:

1. The numerical results depend on the parameters that describe the $\mathrm{Cr}(\mathrm{Re})-\mathrm{Al}_{2} \mathrm{O}_{3}$ bonding. The load-deflection curve represents the overall response of the sample, which can be fitted by different combinations of the interface properties such as fracture energy and cohesive strength. Further information provided in this study by the actual failure mode of the investigated sample permits to discriminate among the possible alternatives.

2. The model is capable of reproducing the experimentally observed force-displacement behavior of microcantilevers with a good accuracy. Not only the force-displacement curves but also the crack propagation paths predicted by the computational model under mixed-mode loading conditions match well with the experimental data.

3. Through the sensitivity analysis, the cohesive strength and the fracture energy of the interface between the metal matrix and ceramic reinforcement in the $\mathrm{Cr}(\mathrm{Re}) / \mathrm{Al}_{2} \mathrm{O}_{3}$ composite manufactured by pressure sintering are estimated to be $0.63 \mathrm{GPa}$ and $50 \mathrm{~J} / \mathrm{m}^{2}$, respectively.

\section{ACKNOWLEDGMENTS}

The micromechanical experiments were performed at the Materials Center Leoben and Montanuniversität Leoben (Austria) during the research stay of Kamil Bochenek supported by the KMM-VIN AISBL fellowship. Part of numerical simulations were carried out during the research stay of Pandi Pitchai at the Institute of Fundamental Technological Research of the Polish Academy of Sciences in Warsaw, supported by 
the KMM-VIN AISBL fellowship. The authors also gratefully acknowledge the financial support under the scope of the COMET program within the K2 Center "Integrated Computational Material, Process and Product Engineering (IC-MPPE)" (Project No. 859480). Daniel Kiener acknowledges financial support from the European Research Council under ERC Grant Agreement No. 771146 (TOUGHIT).

\section{OPEN ACCESS}

This article is licensed under a Creative Commons Attribution 4.0 International License, which permits use, sharing, adaptation, distribution and reproduction in any medium or format, as long as you give appropriate credit to the original author(s) and the source, provide a link to the Creative Commons licence, and indicate if changes were made. The images or other third party material in this article are included in the article's Creative Commons licence, unless indicated otherwise in a credit line to the material. If material is not included in the article's Creative Commons licence and your intended use is not permitted by statutory regulation or exceeds the permitted use, you will need to obtain permission directly from the copyright holder. To view a copy of this licence, visit http://creat ivecommons.org/licenses $/$ by $/ 4.0 /$.

\section{REFERENCES}

1. M.D. Uchic, D.M. Dimiduk, J.N. Florando, and W.D. Nix: Science, 2004, vol. 305, pp. 986-89.

2. Z. Hu, C. Cao, M. Pozuelo, M. Sokoluk, J.-M. Yang, and X. Li: Metall. Mater. Trans. A, 2019, vol. 50A, pp. 4620-31.

3. H. Dugdale, D.E.J. Amstrong, E. Tarleton, S.G. Roberts, and S. Lozano-Perez: Acta Mater., 2013, vol. 61, pp. 4707-13.

4. J. Ast, Th. Przybilla, V. Maier, K. Durst, and M. Göken: J. Mater. Res., 2014, vol. 29, pp. 2129-40.

5. T. Klünsner, S. Wurster, P. Supancic, R. Ebner, M. Jenko, J. Glätzle, A. Püschnel, and R. Pippan: Acta Mater., 2011, vol. 59, pp. 4244-52.

6. M. Jonke, T. Klünsner, P. Supancic, W. Harrer, J. Glätzle, R. Barbist, and R. Ebner: Int. J. Refract. Metals Hard Mater., 2017, vol. 64, pp. 219-24.

7. R. Pippan, S. Wurster, and D. Kiener: Mater. Des., 2018, vol. 159, pp. $252-67$.

8. J. Gong and A. Wilkinson: Philos. Mag. Lett., 2010, vol. 90, pp. 503-12.

9. D.E.J. Armstrong, A.J. Wilkinson, and S.G. Roberts: J. Mater. Res., 2009, vol. 24, pp. 3268-76.
10. D.E.J. Armstrong, A.J. Wilkinson, and S.G. Roberts: Philos. Mag. Lett., 2011, vol. 91, pp. 394-400.

11. S. Wurster, C. Motz, and R. Pippan: Philos. Mag., 2012, vol. 92 , pp. 1803-25.

12. F. Iqbal, J. Ast, M. Göken, and K. Durst: Acta Mater., 2012, vol. 60, pp. 1193-1200.

13. D. Kiener, C. Motz, T. Schöberl, M. Jenko, and G. Dehm: $A d v$. Eng. Mater., 2006, vol. 8, pp. 1119-25.

14. M.G. Mueller, M. Fornabaio, G. Zagar, and A. Mortensen: Acta Mater., 2016, vol. 105, pp. 165-75.

15. V. Pejchal, M. Fornabaio, G. Zagar, and A. Mortensen: J. Mech. Phys. Solids, 2017, vol. 109, pp. 34-49.

16. N. Chawla and K.K. Chawla: Metal Matrix Composites, Springer, New York, NY, 2006.

17. A. Mortensen and T.W. Clyne: European White Book of Fundamental Research in Materials Science, Max-Planck-Institute für Metallforschung, Stuttgart, 2001, pp. 210-16.

18. J.C. Williams and E.A. Starke: Acta Mater., 2003, vol. 51, pp. $5775-99$.

19. D.R. Clarke: J. Am. Ceram. Soc., 1992, vol. 75, pp. 739-59.

20. J.W. Kaczmar, K. Pietrzak, and W. Włosiński: J. Mater. Proc. Technol., 2000, vol. 106, pp. 58-67.

21. A.A. Mazen and A.Y. Ahmed: J. Mater. Eng. Perform., 1998, vol. 7, pp. 393-401.

22. M. Chmielewski, K. Pietrzak, A. Strojny-Nędza, B. Dubiel, and A. Czyrska-Filemonowicz: Int. J. Mater. Res., 2014, vol. 105, pp. $200-07$.

23. M. Chmielewski, K. Pietrzak, M. Basista, and W. Węglewski: Int. J. Refract. Met. Hard Mater., 2016, vol. 54, pp. 196-202.

24. W. Wegglewski, M. Basista, A. Manescu, M. Chmielewski, K. Pietrzak, and Th. Schubert: Composites, Part B, 2014, vol. 67, pp. 119-24.

25. Simpleware ScanIP/FE v.4.3, Simpleware Ltd., Exeter, UK, 2011.

26. ABAQUS/Standard, Release 6.14-1. Dassault Systems Simulia Corporation, Providence, RI, 2014.

27. G. Lin and K.S. Chan: Metall. Mater. Trans. A, 1999, vol. 30A, pp. 3239-51.

28. W. Węglewski, K. Bochenek, M. Basista, Th. Schubert, U. Jehring, J. Litniewski, and S. Mackiewicz: Comput. Mater. Sci., 2013, vol. 77, pp. 19-30.

29. A. Sully and E. Brandes: Chromium, Publ Butterworth, London, 1971.

30. R.G. Munro: J. Am. Ceram. Soc., 1997, vol. 80, pp. 1919-28.

31. P.P. Camanho and C.G. Davila CG: NASA/TM 2002, 211737.

32. G. Alfano and M.A. Crisfield: Int. J. Numer. Methods Eng., 2001, vol. 50 , pp. 1701-36.

33. M.N. Yuan, Y.Q. Yang, C. Li, P.Y. Heng, and L.Z. Li: Mater. Des., 2012, vol. 38, pp. 1-6.

34. Q. Xu and Z. Lu: Int. J. Plast., 2013, vol. 41, pp. 147-64.

35. H. Qing: Mater. Des., 2013, vol. 51, pp. 438-47.

36. Y. Mi, M.A. Crisfield, and G.A.O. Davies: J. Compos. Mater., 1998, vol. 32, pp. 1246-72.

37. X. Lu, M. Fernández, R.S. Bradley, S.D. Rawson, M. Brien, B. Hornberger, M. Leibowitz, G. Tozzi, and P.J. Withers: Acta Biomater., 2019, vol. 96, pp. 400-11.

Publisher's Note Springer Nature remains neutral with regard to jurisdictional claims in published maps and institutional affiliations. 